\title{
PURIFICAÇÃO DE METABÓLITOS FÚNGICOS COM EFEITOS TÓXICOS SOBRE Meloidogyne incognita*
}

\author{
GERALDO H. SILVA ${ }^{1 * *}$, DENILSON F. OLIVEIRA ${ }^{2} \&$ VICENTE P. CAMPOS $^{2}$
}

\begin{abstract}
${ }^{1}$ Departamento de Química, Universidade Federal de Lavras, e-mail: geraldoh@posgrad.iq.unesp.br; ${ }^{2}$ Departamento de Química, Universidade Federal de Lavras, e-mail: denilson@ufla.br; ${ }^{3}$ Departamento de Fitopatologia, Universidade

Federal de Lavras, Cx. Postal 37, CEP 37200-000, Lavras, MG
\end{abstract}

(Aceito para publicação em 18/09/2002)

Autor para correspondência: Denilson F. Oliveira

SILVA, G.H., OLIVEIRA, D.F. \& CAMPOS, V.P. Purificação de metabólitos fúngicos com efeitos tóxicos sobre Meloidogyne incognita. Fitopatologia Brasileira 27:594-598. 2002.

\begin{abstract}
RESUMO
Objetivando o desenvolvimento de novas metodologias de controle de fitonematóides, este trabalho buscou purificar as substâncias nematicidas produzidas por Cunninghamella elegans, Fusarium sp., Paecilomyces lilacinus e P. variotii. Esses fungos foram cultivados em meio líquido Czapek-Dox durante 15 dias, a $25{ }^{\circ} \mathrm{C}$, em agitador orbital. Em seguida, filtraram-se as misturas, o que permitiu a obtenção de soluções que foram concentradas sob vácuo e submetidas à purificação direcionada por testes in vitro com Meloidogyne incognita. Observou-se que os filtrados de P. lilacinus e P. variotii perdiam suas atividades nematicidas após a concentração sob vácuo,

sugerindo que as substâncias ativas produzidas por esses fungos são consideravelmente voláteis. Para o filtrado de Fusarium sp., observou-se perda total da atividade contra $M$. incognita após fracionamento em coluna de sílica gel, indicando instabilidade da substância nematicida frente às condições empregadas. Do filtrado de C. elegans isolou-se uma substância que, em solução aquosa na concentração de 250 ppm, imobilizou 94\% dos juvenis do segundo estádio de $M$. incognita expostos a tal solução durante $48 \mathrm{~h}$.

Palavras-chave adicionais: metabólitos fúngicos, nematóide, nematicida.

\section{ABSTRACT}

Purification of fungal metabolites with toxic effects on Meloidogyne incognita

In a search for new molecules toxic to plant parasitic nematodes, procedures were set up to purify nematode toxic molecules produced by Cunninghamella elegans, Fusarium sp., Paecilomyces lilacinus and $P$. variotii. Those fungi were grown in Czapek-Dox liquid medium during 15 days, at $25{ }^{\circ} \mathrm{C}$, in an orbital shaker. After fungus mycelium removal by filtration, the solutions were concentrated under vacuum and submitted to purification, guided by in vitro assays with Meloidogyne incognita juveniles. As a result, it was observed that P. lilacinus

and P.variotii filtrates lost their activity after vacuum concentration, which suggests that the nematocides produced by those fungi are considerably volatile. In the case of Fusarium sp. filtrate, the active substance seems to be unstable, as the activity against $M$. incognita juveniles completely disappeared after chromatography in a silica gel column. The C. elegans filtrate rendered one isolated substance that immobilized $94 \%$ of the $M$. incognita juveniles exposed during $48 \mathrm{~h}$ to an aqueous solution of the substance at $250 \mathrm{ppm}$.
\end{abstract}

\section{INTRODUÇÃO}

Nematóides causam extensos danos a diversas culturas, ocasionando grandes perdas na produção agrícola (Campos, 1992). Conseqüentemente, o controle desses patógenos é vital para a exploração agrícola comercial, o que pode ser feito com o uso de nematicidas sintéticos, resultantes da indústria petroquímica (Campos et al., 1990; Campos, 1997). Essas substâncias podem contaminar águas subterrâneas, intoxicar aplicadores ou deixar resíduos em alimentos, o que fez surgir pesquisas sobre o uso de moléculas menos danosas ao homem

\footnotetext{
*Parte da Dissertação de Mestrado do primeiro autor. Universidade Federal de Lavras (2001).

**Bolsista do CNPq
}

e ao meio ambiente. Uma possível alternativa consiste no emprego de fungos, uma vez que vários desses microrganismos produzem metabólitos tóxicos aos nematóides (Mankau, 1979). Tais substâncias podem afetar a motilidade (Costa, 2000), capacidade de penetração na planta, atração do juvenil pelo hospedeiro, eclosão ou casuar a morte desses fitoparasitas (Kerry et al., 1984), podendo atuar como moléculas nematostáticas ou nematicidas (Saifullah, 1996; Hallman \& Sikora, 1996).

Nas interações entre fungos e nematóides, acredita-se que os metabólitos fúngicos podem ser empregados tanto no ataque quanto na defesa contra fitonematóides (Stadler et $a l ., 1993)$. No caso dos fungos nematófagos, por exemplo, Barron \& Thorn (1987) observaram que vários produzem toxinas que podem estar envolvidas na imobilização e morte 
Purificação de metabólitos fúngicos com efeitos tóxicos sobre Meloidogyne...

dos nematóides. De forma análoga, também já se tem conhecimento de fungos que, para não serem ingeridos por nematóides, protegem as hifas com substâncias tóxicas (Hutchison et al., 1996; Riffle, 1967, 1971). Há, ainda, fungos que aparentemente não interagem diretamente com nematóides fitoparasitas, mas são capazes de produzir substâncias com propriedades nematicidas (Chen et al., 2000). Como exemplo pode-se citar Fusarium equiseti (Corda) Sacc. (1886). Nitao et al. (1999) cultivaram este fungo em meio líquido e, após filtração do meio, observaram considerável atividade nematicida do líquido obtido em testes com Meloidogyne incognita (Kofoid \& White) Chitwood. De forma análoga, Hallman \& Sikora (1996) e Costa (2000) obtiveram filtrados de vários isolados de Fusarium oxysporum Schlecht tóxicos a nematóides.

Cientes da importância de isolar e identificar metabólitos fúngicos tóxicos a nematóides, Kimura et al. (1996) submeteram o filtrado de Aspergillus melleus Yukawa às técnicas de partição líquido-líquido e cromatográficas, o que permitiu isolar a aspirona, que é a substância tóxica a Pratylenchus penetrans (Cobb, 1917) Filipjev \& Schuurmans Stekhoven, 1941 produzida pelo referido fungo. De forma análoga, Quaghebeur et al. (1994) isolaram duas substâncias nematicidas do filtrado fúngico de Cylindrocarpon olidum Wollenw. (Wollenw.); Kawazu et al. (1993) obtiveram as bursaphelocidas A e B do filtrado de um isolado identificado como D1084.

Em decorrência do exposto, em estudo preliminar, vários fungos tiveram os filtrados correspondentes submetidos a testes toxicológicos in vitro e in vivo com $M$. incognita, o que permitiu observar que aqueles obtidos de Cunninghamella elegans Lendner, Fusarium sp., Paecilomyces lilacinus (Thom) Samson e Paecilomyces variotii Bainer, eram os mais ativos contra o referido nematóide (Costa, 2000). Com base em tais resultados, o presente trabalho teve por objetivo purificar as substâncias nematicidas produzidas por esses fungos, através de fracionamentos direcionados por testes in vitro com M. incognita.

\section{MATERIAL E MÉTODOS}

\section{Obtenção dos filtrados fúngicos}

Os fungos C. elegans, Fusarium sp., P. lilacinus e $P$. variotii, previamente isolados e selecionados por Costa (2000), foram repicados para placas de Petri contendo meio de cultura batata-dextrose-ágar. Após sete dias de incubação a $27{ }^{\circ} \mathrm{C}$, discos de $5 \mathrm{~mm}$ de diâmetro dessas culturas foram colocados em frascos de $500 \mathrm{ml}$, contendo $200 \mathrm{ml}$ de meio líquido CzapekDox $\left(0,5 \mathrm{~g}\right.$ de $\mathrm{KCl}, 1 \mathrm{~g}$ de $\mathrm{KH}_{2} \mathrm{PO}_{4}, 2 \mathrm{~g}$ de $\mathrm{NaNO}_{3}, 30 \mathrm{~g}$ de sacarose, $0,01 \mathrm{~g}$ de $\mathrm{FeSO}_{4} \cdot \mathrm{H}_{2} \mathrm{O}$ e $0,5 \mathrm{~g}$ de $\mathrm{MgSO}_{4} .7 \mathrm{H}_{2} \mathrm{O}$ por $1000 \mathrm{ml}$ de água destilada), previamente esterilizado a $120^{\circ} \mathrm{C}$ por $20 \mathrm{~min}$. Colocaram-se seis discos de cada cultura por frasco, que foi mantido em incubadora a $25^{\circ} \mathrm{C}$, com agitação orbital por 15 dias. Após esse período, a cultura foi filtrada em papel Whatman $\mathrm{n}^{\circ} 1$, por duas vezes, com o auxílio de uma bomba de vácuo, obtendo-se, assim, as fases líquidas denominadas filtrados fúngicos. Cerca de 11 de cada filtrado foi liofilizado e mantido a $4{ }^{\circ} \mathrm{C}$, até ser submetido ao fracionamento.

\section{Fracionamento dos filtrados fúngicos por extração e precipitação}

O fracionamento dos filtrados de C. elegans, Fusarium sp., $P$. lilacinus e $P$. variotii seguiu o esquema mostrado na Figura 1.

Alíquotas das frações combinadas de acetato de etila (AcOEt) e de metanol foram concentradas sob vácuo e dissolvidas em solução de Tween 80 a $1 \%(\mathrm{~g} / \mathrm{ml})$ em água, até volume 4,4 vezes superior ao das alíquotas. As soluções resultantes foram submetidas ao teste in vitro com juvenis do segundo estádio (J2) de M. incognita.

No caso específico de C. elegans, ao se adicionar AcOEt ao filtrado concentrado houve a formação de precipitado (A1), que foi separado por centrifugação. Após a separação de A1, o sobrenadante foi extraído conforme o processo descrito anteriormente (Figura 1). O precipitado A1, um sólido amarelado, foi consecutivamente lavado com clorofórmio, metanol e $\mathrm{HCl} 2 \mathrm{M}$. Depois da concentração das frações clorofórmica e metanólica sob vácuo, prepararamse soluções a $500 \mathrm{ppm}(500 \mu \mathrm{g} / \mathrm{ml}) \mathrm{em}$ Tween 80 a $1 \%$ para os testes in vitro. Quanto à fração em $\mathrm{HCl} 2 \mathrm{M}$, foi alcalinizada com hidróxido de amônio $\left(\mathrm{NH}_{4} \mathrm{OH}\right)$ concentrado, dando lugar a formação de um novo precipitado (A2), que foi separado por centrifugação. Após a secagem, foram preparadas soluções a 500 e $250 \mathrm{ppm}$ de $\mathrm{A} 2 \mathrm{em} \mathrm{HCl} 10^{-5} \mathrm{M}$ para os testes in vitro.

\section{Fracionamento do extrato em acetato de etila do filtrado de Fusarium sp.}

$\mathrm{O}$ extrato em acetato de etila, obtido a partir de $4 \mathrm{lde}$ filtrado de Fusarium sp., foi submetido à cromatografia em coluna com 2 × $20 \mathrm{~cm}$ de sílica gel. Os solventes utilizados

Filtrado fúngico - 1 ।

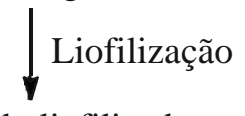

Filtrado liofilizado

1) $30 \mathrm{ml} \mathrm{de} \mathrm{H}_{2} \mathrm{O}$

2) Extração com AcOEt $(4 \times 20 \mathrm{ml})$

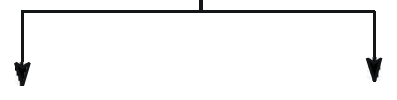

Frações AcOEt

$(80 \mathrm{ml})$

Frações aquosas

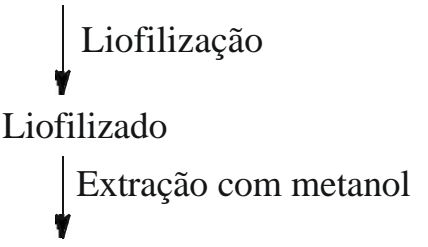

Frações metanólicas

FIG. 1 - Fluxograma da extração dos filtrados fúngicos de Cunninghamella elegans, Fusarium sp., Paecilomyces lilacinus e $P$. variotii. 
na eluição das substâncias através da coluna foram hexano, AcOEt e metanol. Coletaram-se 51 frações, que foram combinadas de acordo com o observado por cromatografia em camada delgada. Com isso, ao final havia doze frações: Fs1-Fs12. A fração Fs11 foi submetida a nova cromatografia em coluna com 2 × $20 \mathrm{~cm}$ de sílica gel. Os solventes utilizados para eluição foram clorofórmio e metanol com $5 \%$ de $\mathrm{NH}_{4} \mathrm{OH}$. Coletaram-se 24 frações que, ao serem combinadas de acordo com os resultados das análises por cromatografia em camada fina, forneceram as frações Fs13-Fs16. Alíquotas das frações foram concentradas sob vácuo para darem origem a resíduos, com os quais se prepararam soluções a $500 \mathrm{ppm}$ em Tween 80 a $1 \%$ ou $\mathrm{HCl} 10^{-5} \mathrm{M}$, para serem submetidas aos testes in vitro.

\section{Análise do sólido A2, obtido de Cunninghamela elegans}

Através de análise por cromatografia em camada fina com sílica gel, empregando-se diclorometano/metanol (1:1) como eluente, verificou-se que havia apenas uma mancha com Rf (distância percorrida pela substância/distância percorrida pelo eluente) igual a 0,47 , que foi revelada com ninidrina (Harborne, 1998). Durante a tentativa de observar o ponto de fusão, A2 começou a decompor em $195{ }^{\circ} \mathrm{C}$, antes de fundir. $\mathrm{Na}$ análise por espectrometria de infravermelho (Shriner et al., 1983), em pastilha de $\mathrm{KBr}$, obtiveram-se as seguintes bandas: $3330,1654,1402,1082,1008,887,565$ e $540 \mathrm{~cm}^{-1}$

\section{Obtenção de ovos de Meloidogyne incognita}

Ovos de $M$. incognita foram obtidos de raízes de tomateiro (Lycopersicon esculentum Mill.) (cv. Kada) pela técnica de Hussey \& Barker (1973), modificada por Boneti \& Ferraz (1981). A suspensão de ovos obtida foi submetida a desinfestação superficial pela técnica de Coolen \& D'Herde (1972).

Teste de motilidade e mortalidade de juvenis do segundo estádio (J2) de Meloidogyne incognita em placa de Petri

Os ovos obtidos foram colocados em câmara de eclosão formada com tela e papel de espessura fina, posicionados em béquer esterilizado, sem aeração, para evitar contaminação. Os $\mathrm{J} 2$ obtidos a cada $24 \mathrm{~h}$ eram contados até que perfizessem número suficiente para a montagem do experimento. Em placa de Petri de 4,5 cm de diâmetro foi colocado $1 \mathrm{ml} \mathrm{de}$ suspensão contendo $100 \mathrm{~J} 2$ de $M$. incognita e $5 \mathrm{ml}$ do tratamento. Empregaram-se cinco repetições em delineamento inteiramente casualizado (DIC), sendo testemunhas os veículos aquosos empregados nas solubilizações das amostras. As avaliações de motilidade foram realizadas com 24 e $48 \mathrm{~h}$ de exposição do J2 às amostras. Após a última avaliação de motilidade, os $\mathbf{J} 2$ foram recolhidos em uma peneira de 0,025 $\mathrm{mm}$ e transferidos para água. Foram então, lavados em água corrente até a retirada da amostra e colocados novamente nas placas de Petri. Após 24 h, foi realizada a avaliação de mortalidade. Efetuaram-se todas as contagens em microscópio de objetiva invertida, sendo os números obtidos transformados em percentagem para serem submetidos à análise estatística.
Teste de motilidade de juvenis do segundo estádio (J2) de $M$. incognita em placa Elisa

Os $\mathbf{J} 2$ eclodidos foram suspensos em água e a suspensão calibrada para $1.250 \mathrm{~J} 2 / \mathrm{ml}$. Cem microlitros da amostra a ser testada e uma alíquota de $20 \mu \mathrm{l}$ contendo $25 \mathrm{~J} 2$ foram colocados em células de placa Elisa. Realizaram-se cinco repetições, sendo utilizadas como controles as soluções aquosas empregadas na dissolução das amostras. As avaliações consistiram na contagem de $\mathrm{J} 2$ móveis e imóveis com o auxílio de microscópio de objetiva invertida. Os dados foram transformados para percentagem e submetidos à análise de variância.

Com as amostras provenientes de Fusarium sp., as avaliações foram efetuadas com 24 e $48 \mathrm{~h}$. Para as amostras de C. elegans, as avaliações foram realizadas com 24,36 e $48 \mathrm{~h}$.

\section{RESULTADOS E DISCUSSÃO}

Inicialmente, buscou-se extrair as substâncias ativas contra $M$. incognita através do uso de AcOEt, que é um solvente de polaridade intermediária, com emprego já relatado na purificação de substâncias nematicidas de outros filtrados fúngicos (Kawazu et al., 1993; Quaghebeur et al., 1994; Kimura et al., 1996; Nitao et al., 1999). A exposição de J2 de M. incognita ao extrato em AcOEt de Fusarium sp. por 24 e $48 \mathrm{~h}$ reduziu a motilidade dos $\mathrm{J} 2$ a $56 \%$ e $5 \%$, respectivamente (Tabela 1). A percentagem de $\mathrm{J} 2$ vivos foi de apenas $12 \%$, o que corresponde a um valor 7,2 vezes menor do que $o$ observado para as testemunhas (Tabela 1).

Como ainda julgava-se possível que as frações aquosas contivessem substâncias ativas contra $M$. incognita, foram liofilizadas e lavadas com metanol, que apresenta polaridade mais acentuada do que AcOEt. No entanto, nenhuma das frações metanólicas (Figura 1) mostrou-se ativa (Tabela 1).

No caso específico de P. lilacinus, cujo filtrado promoveu até $99 \%$ de mortalidade de $\mathbf{J} 2$ de $M$. incognita em estudo preliminar (Costa, 2000), o ácido acético já tinha sido caracterizado como a substância responsável por tal atividade (Djian et al., 1991). Como tal substância é relativamente volátil, provavelmente foi perdida durante a etapa de liofilização. Talvez o mesmo tenha ocorrido com $P$. variotii, cujo filtrado também apresentava atividade contra $M$. incognita (Costa, 2000).

Como a fração em AcOEt de Fusarium sp. era a única apresentando atividade contra $M$. incognita (Tabela 1), ela foi submetida ao processo de purificação por cromatografia em coluna de sílica gel, utilizada com sucesso no isolamento de substâncias do filtrado fúngico de F. equiseti (Nitao et al., 1999). Infelizmente, as frações resultantes não se mostraram diferentes das testemunhas nos testes in vitro, indicando que a substância nematicida era instável frente às condições empregadas.

A formação do sólido A1 obtido de C. elegans pode ter ocorrido devido à remoção de substâncias surfactantes da fase aquosa pelo solvente acetato de etila. $\mathrm{O}$ extrato de A1 
Purificação de metabólitos fúngicos com efeitos tóxicos sobre Meloidogyne...

TABELA 1- Efeito de extratos fúngicos em metanol e acetato de etila na motilidade e mortalidade de juvenis do segundo estádio (J2) de Meloidogyne incognita

\begin{tabular}{|c|c|c|c|}
\hline \multirow[t]{2}{*}{ Tratamento } & \multicolumn{2}{|c|}{$\begin{array}{l}\text { (\%) J2 } \\
\text { móveis }\end{array}$} & \multirow{2}{*}{$\begin{array}{c}(\%) \mathrm{J} 2 \\
\text { vivos } \\
72 \mathrm{~h} \\
\end{array}$} \\
\hline & $24 \mathrm{~h}$ & $48 \mathrm{~h}$ & \\
\hline \multicolumn{4}{|c|}{ Extratos em acetato de etila de: } \\
\hline Cunninghamela elegans & $84 b^{*}$ & $83 b^{*}$ & $81 b^{*}$ \\
\hline Fusarium sp. & $56 \mathrm{a}$ & $5 \mathrm{a}$ & $12 \mathrm{a}$ \\
\hline Paecilomyces lilacinus & $94 \mathrm{~b}$ & $90 \mathrm{~b}$ & $84 \mathrm{~b}$ \\
\hline P. variotii & $96 \mathrm{~b}$ & $82 \mathrm{~b}$ & $85 \mathrm{~b}$ \\
\hline \multicolumn{4}{|l|}{ Extratos em metanol de: } \\
\hline C. elegans & $91 \mathrm{~b}$ & $85 \mathrm{~b}$ & $87 \mathrm{~b}$ \\
\hline Fusarium sp. & $90 \mathrm{~b}$ & $90 \mathrm{~b}$ & $90 \mathrm{~b}$ \\
\hline P. lilacinus & $91 \mathrm{~b}$ & $77 \mathrm{~b}$ & $88 \mathrm{~b}$ \\
\hline P. variotii & $92 \mathrm{~b}$ & $78 \mathrm{~b}$ & $93 \mathrm{~b}$ \\
\hline \multicolumn{4}{|l|}{ Testemunhas } \\
\hline água & $93 \mathrm{~b}$ & $91 \mathrm{~b}$ & $87 \mathrm{~b}$ \\
\hline Tween 80 a $1 \%$ & $90 \mathrm{~b}$ & $87 \mathrm{~b}$ & $87 \mathrm{~b}$ \\
\hline
\end{tabular}

em metanol reduziu a motilidade de $\mathrm{J} 2$ de $M$. incognita a $78 \%$ com exposição de $48 \mathrm{~h}$ (Tabela 2), demonstrando fraca atividade tóxica. Já o precipitado A2, mesmo em concentração de $250 \mathrm{ppm}$, reduziu significativamente a motilidade de $\mathrm{J} 2$ após $36 \mathrm{~h}$ (Tabela 2). Na concentração de $500 \mathrm{ppm}$ a motilidade de $\mathrm{J} 2$ foi de apenas $8 \%$ em $36 \mathrm{~h}$ de exposição e caiu para $1 \%$ com $48 \mathrm{~h}$ de exposição (Tabela 2 ).

O sólido A2 foi considerado puro, uma vez que se observou apenas uma mancha quando analisado por cromatografia em camada fina. Buscou-se confirmar o resultado da análise cromatógrafica por meio de observação da fusão de A2, já que a amplitude da faixa de temperatura na qual a transição da fase sólida para a líquida ocorre pode indicar o grau de pureza da substância (Shriner et al., 1983). No entanto, isso não foi possível, pois A2 começou a decompor-se antes de fundir-se.

O fato de esse material (A2) ser solúvel em soluções aquosas fortemente ácidas e insolúvel naquelas com $\mathrm{pH}$ acima de 5, indica que possui átomos de nitrogênio cujos pares de elétrons não se encontram tão disponíveis como em uma amina simples, que geralmente não precisa de valores de $\mathrm{pH}$ tão baixos para ser solubilizada em soluções aquosas (Shriner et al., 1983). A presença de um átomo de nitrogênio é uma proposta amparada na revelação de $\mathrm{A} 2$ com ninidrina durante as análises por cromatografia em camada fina, já que isso é o que tende a ocorrer quando a substância analisada possui grupamentos $\mathrm{NH}_{2}$ (Shriner et al., 1983; Harborne, 1998).

Vale destacar as bandas em $1654 \mathrm{~cm}^{-1}$ no espectro infravermelho, que podem ser provenientes de ligações $\mathrm{C}=$ $\mathrm{O}$ de grupo amida. Esta hipótese obteve suporte devido à banda em $1.082 \mathrm{~cm}^{-1}$, que pode ser decorrente de ligação $\mathrm{C}-\mathrm{N}$. Também se deve mencionar a banda em $565 \mathrm{~cm}^{-1}$, que pode indicar a presença de um átomo de cloro na molécula (Lambert et al., 1998).
TABELA 2 - Efeito das frações obtidas do precipitado A1 do filtrado de Cunninghamella elegans na motilidade de juvenis do segundo estádio (J2) de Meloidogyne incognita

\begin{tabular}{|c|c|c|c|}
\hline \multirow{2}{*}{ Tratamento } & \multicolumn{3}{|c|}{ (\%) de J2 móveis * } \\
\hline & $24 \mathrm{~h}$ & $36 \mathrm{~h}$ & $48 \mathrm{~h}$ \\
\hline \multicolumn{4}{|l|}{ Testemunhas } \\
\hline $\mathrm{HCl} 10^{-5} \mathrm{M}$ & $94 \mathrm{a}$ & $93 \mathrm{c}$ & $91 \mathrm{c}$ \\
\hline Tween 80 a $1 \%$ & $95 \mathrm{a}$ & $92 \mathrm{c}$ & $90 \mathrm{c}$ \\
\hline Água & $96 \mathrm{a}$ & $95 \mathrm{c}$ & $94 \mathrm{c}$ \\
\hline \multicolumn{4}{|l|}{ Frações de C. elegans } \\
\hline Precipitado A2 500ppm & $94 \mathrm{a}$ & $8 \mathrm{a}$ & $1 \mathrm{a}$ \\
\hline Precipitado A2 250ppm & $93 \mathrm{a}$ & $54 \mathrm{~b}$ & $6 \mathrm{a}$ \\
\hline Extrato $\mathrm{MeOH}$ de A1 a 500ppm & $92 \mathrm{a}$ & $92 \mathrm{c}$ & $78 \mathrm{~b}$ \\
\hline Extrato $\mathrm{CHCl}_{3}$ de $\mathrm{A} 1$ a $500 \mathrm{ppm}$ & $93 \mathrm{a}$ & $92 \mathrm{c}$ & $92 \mathrm{c}$ \\
\hline
\end{tabular}

Ainda é importante relatar que A2 se mostrou insolúvel em metanol, diclorometano, éter etílico, AcOEt, piridina, ácido acético, acetona, clorofórmio e dimetil sulfóxido, o que é uma característica relativamente comum de bases purínicas ou pirimidínicas sem ou com substituintes pequenos (Harborne, 1998).

\section{AGRADECIMENTOS}

Os autores agradecem à Fundação de Amparo à Pesquisa do Estado de Minas Gerais (FAPEMIG) pelo apoio financeiro e ao Conselho Nacional de Pesquisa e Desenvolvimento Científico e Tecnológico (CNPq) por uma bolsa de Mestrado.

\section{REFERÊNCIAS BIBLIOGRÁFICAS}

BARRON, G.L. \& THORN, R.G. Destruction of nematodes by species of Pleurotus. Canadian Journal of Botany 65:774-778. 1987.

BONETI, J.I.S. \& FERRAZ, S. Modificação do método de Hussey e Barker para extração de ovos de Meloidogyne exigua de cafeeiro. Fitopatologia Brasileira 6:553. 1981. (Resumo).

CAMPOS, V.P. Controle de doenças: Doenças causadas por nematóides In: Vale, F.X.R. \& Zambolim, L. (Eds.). Controle de Doenças de Plantas. Volume 1. Viçosa. UFV. 1997. pp. 141179.

CAMPOS, V.P. Implicação da sobrevivência dos nematóides em solos e raízes de plantas no controle dos fitopatógenos. Informe Agropecuário 16:15-16. 1992.

CAMPOS, V.P., SIVAPALAN, P. \& GNANAPRAGASAM, N.C. Nematode parasites of coffee, cocoa and tea. In: Luc, M., Sikora, R.A. \& Bridge, J. (Eds.). Plant Parasitic Nematodes in Subtropical and Tropical Agriculture. Wallingford. CABI Publishing, CAB International. 1990. pp.387-430.

CHEN, S.Y., DICKSON, D.W. \& MITCHELL, D.J. Viability of Heterodera glycines exposed to fungal filtrates. Journal of Nematology 32:190-197. 2000.

COOLEN, W.A. \& D'HERDE, C.J. A Method for the Quantitative Extraction of Nematodes from Plant Tissue. Ghent. State Agriculture Research Centre. 1972. 


\section{G.H. Silva et al.}

COSTA, M.J.N. Filtrados de culturas fúngicas e estercos animais, com ação antagonista a Meloidogyne incognita (Kofoid \& White) Chitwood (Tese de Mestrado). Lavras: Universidade Federal de Lavras. 2000.

DJIAN, C., PIJAROWSKI, L., PONCHET, M., ARPIN, N. \& BONVIN, F.J. Acetc acid: a selective nematicidal metabolite from culture filtrates of Paecilomyces lilacinus (Thom) Samson and Trichoderma longiabrachiatum Rifai. Nematologica 7:101112. 1991.

HALLMAN, J. \& SIKORA, R.A. Toxicity of fungal endophyte secondary metabolites to plant parasitic nematodes and soilborne plant pathogenic fungi. European Journal of Plant Pathology 102:155-162. 1996.

HARBORNE, J.B.. Phytochemical Methods. A Guide to Modern Techniques of Plant Analysis. $3^{\text {rd }}$ ed. London. Chapman \& Hall. 1998.

HUSSEY, R.S. \& BARKER, K.R. A comparison of methods for collecting inocula of Meloidogyne spp. including a new technique. Plant Disease Reporter 57:1025-1028. 1973.

HUTCHISON, L.J., MADZIA, S.E. \& BARRON, G.L. The presence and antifeedant function of toxin producing secretory cells on hyphae of the lawn-inhabiting agaric Conocybe lactea. Canadian Journal of Botany 74:431-434. 1996.

KAWAZU, K., MURAKAMI, T., ONO, Y., KANZAKI, H., KOBAYASHI, A., MIKAWA, T. \& YOSHIKAWA, N. Isolation and characterization of two novel nematicidal dipeptides from an imperfect fungus, strain D1084. Bioscience, Biotecnology and Biochemistry 5:98-101. 1993.

KERRY, B.R., SIMONN, A. \& ROVIRA, A.D. Observations on the introductions of Verticillium chlamydosporium and other parasitic fungi into soil for control of the cereal cyst-nematode Heterodera avenae. Annals of Applied Biology 105:509-516. 1984.
KIMURA, Y., NAKAHARA, S. \& FUJIKOKA, S. Aspyrone, a nematicidal compound isolated from the fungus Aspergillus melleus. Bioscience Biotechnology and Biochemistry 60:13751376. 1996.

LAMBERT, J.B., SHURVELL, H.F., LIGHTNER, D.A. \& COOKS, R.G. Organic Structural Spectroscopy. New Jersey. Prentice Hall. 1998.

MANKAU, R. Biocontrol: fungi as nematode control agents. Journal of Nematology 12:1- 4. 1979.

NITAO, J.K., MEYER, S.L.F. \& CHITWOOD, D.J. In vitro assays of Meloidogyne incognita and Heterodera glycines for detection of nematode-antagonistic fungal compounds. Journal of Nematology 31:172-183. 1999.

QUAGHEBEUR, K., COOSEMANS, J., TOPPET, S. \& COMPERNOLLE, F. Canniabioci- and 8Chlorocannabiorcichromenic acid as fungal antagonists from Cylindrocarpom olidum. Phytochemistry 37:159-161. 1994.

RIFFLE, J.W. Effect of an Aphelenchoides species on growth of a mycorrhizal and a pseudomycorrhizal fungus. Phytopathology 57:541-544. 1967.

RIFFLE, J.W. Mycorrhizae. Proceedings, $1^{\text {st }}$ North Americam Conference on Mycorrhizae. USDA Forest Service Misc. Publ. 1189. Washington, D. C. 1971. pp.97-113.

SAIFULLAH, N. Nematicidal and nematostatic effect of cell-free culture filtrates of Verticillium chlamydosporium Goddard in vitro. Afro Asian Journal of Nematology 6:32-35. 1996.

SHRINER, R.L., FUSON, R.C., CURTIN,D. Y. \& MORRILL, T.C. Identificação Sistemática dos Compostos Orgânicos. 6a . ed. Portland. Book News, Inc. 1983

STADLER, M., ANKE, H. \& STERNER, O. Linoleic-acid. The nematocidal principle of several nematophagous fungi and its production in trap-forming submerged cultures. Archives of Microbiology 160:401-405. 1993. 